\title{
Toll-like receptor 4 polymorphisms and susceptibility to multiple autoimmune diseases: evidence based on pooled analysis
}

\author{
XIAO-QIN WANG ${ }^{l}, K U I Z H A N G^{2}, D I N G X I O N G^{3}$ \\ ${ }^{1}$ Sichuan University, China \\ ${ }^{2}$ Zunyi Medical College, China \\ ${ }^{3}$ Meishan People's Hospital, China
}

\begin{abstract}
Background: Toll-like receptor 4 (TLR4) is known to activate the nuclear factor $\kappa B(N F-\kappa B)$ and subsequent gene expression such as cytokines and adhesion molecules. That may subsequently reduce the risk of autoimmune diseases (ADs). However, the results of molecular epidemiological studies remain inconsistent.

Material and methods: The PubMed, Embase, CNKI databases were searched for all articles available. The OR corresponding to the $95 \%$ confidence interval (95\% CI) was used to assess the association between TLR4 polymorphisms and the risk of ADs.

Results: The TLR4 Asp299Gly and TLR4 Thr399Ile polymorphisms were not associated significantly with a risk of ADs (Asp299Gly: OR =0.86, 95\% CI: 0.74-1.00 for G vs. $A$ and $O R=0.87,95 \%$ CI: 0.74-1.01 for $A G / G G$ vs. AA, respectively; Thr399Ile: $O R=0.77,95 \%$ CI: 0.57-1.05 for $T$ vs. $C$ and OR $=0.79,95 \%$ CI: 0.58-1.09 for TT/CT vs. CC, respectively).

Conclusions: This meta-analysis suggested that TLR4 Asp299Gly and TLR4 Thr399Ile polymorphisms were not involved in the development of ADs. However, well-designed studies with a larger sample size should be conducted to confirm this result.
\end{abstract}

Key words: autoimmune diseases, Toll-like receptor 4, single nucleotide polymorphism, meta-analysis, SNP.

(Centr Eur J Immunol 2013; 38 (3): 380-387)

\section{Introduction}

Toll-like receptors (TLRs) are members of a family of receptors encoded by different TLR genes (TLR1-13) that are expressed in many tissues and cell types and participate in antigen recognition. The participation of TLRs in the activation of the innate immune response suggests their possible role as candidate genes in the development of autoimmune diseases [1].

Human Toll-like receptor 4 (TLR4) gene is located on chromosome 9q32-q33, and contains four exons. Toll-like receptor 4 encodes a major endotoxin signaling receptor that plays a fundamental role in pathogen recognition and activation of innate immunity. Two non-synonymous SNPs rs498690 (A896G) and rs4986791 (C1196T) in exon 3 lead to Asp299Gly and Thr399Ile amino acid substitutions, respectively. These SNPs are located in the coding sequence, affect TLR-4 extracellular domain. Individuals possessing a co-segregating polymorphism in TLR-4 (Asp299Gly and Thr399Ile) are hyporesponsive to LPS and are more susceptible to Gram-negative bacterial infections $[2,3]$. In Asian populations, the prevalence of $r s 498690$ and $r s 4986791$ is very low. Several studies have demonstrated the absence of $r s 498690$ and $r s 4986791$ in the Chinese population [4-6] and in the Korean population [7].

In fact, in previous meta-analyses TLR4 polymorphisms appeared to be correlated with Crohn's disease, ulcerative colitis [8], vasculitis [9] and cancer [10], but not with sepsis [11], rheumatoid arthritis, ankylosing spondylitis [1214], and atherosclerosis [15]. To date, a number of molecular epidemiological studies have been done to evaluate the association between TLR4 Asp299Gly and Thr399Ile polymorphisms and several autoimmune diseases (ADs) including type 1 diabetes (T1DM) [16], celiac disease (CED) [16, 
17], rheumatoid arthritis (RA) [18-21], multiple sclerosis (MS) [22, 23], and systemic lupus erythematosus (SLE) [19] in Caucasians. However, the results remained inconsistent.

Considering that a relatively lower frequency of the minor allele and a single study might have been underpowered to detect the overall effects, quantitative syntheses of the accumulated data from different studies were deemed important to provide evidence on the associations of TLR4 Asp299Gly and Thr399Ile polymorphisms and ADs risk. So, we carried out this meta-analysis on all published case-control studies to estimate the overall ADs risk of Asp299Gly and Thr399Ile polymorphisms and to quantify heterogeneity between the individual studies as well as to investigate the existence of a potential publication bias.

\section{Material and methods}

\section{Publication search and inclusion criteria}

We searched the PubMed, Embase, CNKI (China National Knowledge Infrastructure) databases for all articles within a range of published years from 2000 to 2012 on the association between TLR4 Asp299Gly and Thr399Ile polymorphisms and ADs risk (last search was updated on 20 October 2012). The following terms were used in this search: 'Toll-like receptor-4 or TLR4' and 'autoimmune disease or type 1 diabetes or celiac disease or rheumatoid arthritis or multiple sclerosis or Grave's disease or Wegener's granulomatosis or psoriasis or primary sicca syndrome or systemic lupus erythematosus or inflammatory bowel disease' and 'polymorphism or polymorphisms'. In order to identify the relevant publications, the references cited in the research papers were also scanned.

Studies testing the association between TLR4 Asp299Gly and Thr399Ile polymorphisms and ADs risk were included if all of the following conditions were met: (a) the publication was a case-control study; (b) evaluation of the association of TLR4 Asp299Gly and/or Thr399Ile polymorphisms and ADs risk; (c) the ADs diagnosis complied with the diagnosis criteria of the World Health Organization (WHO); (d) the study reported OR or data for their calculation; and (e) the study was published in English.

\section{Data extraction}

Data from these studies were extracted by Xiao-qin Wang and Kui Zhang. Publications were read by Xiao-qin Wang in order to check original data extraction. Finally, the data for this meta-analysis were available from eight casecontrol studies for the Asp299Gly polymorphism, including 3317 cases and 3131 controls, and three studies were available for the Thr399Ile polymorphism, including 815 cases and 479 controls (as shown in Fig. 1). The following
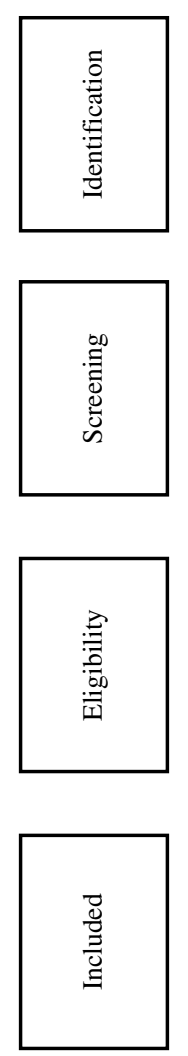

ig. 1. Flowchart for identification of studies

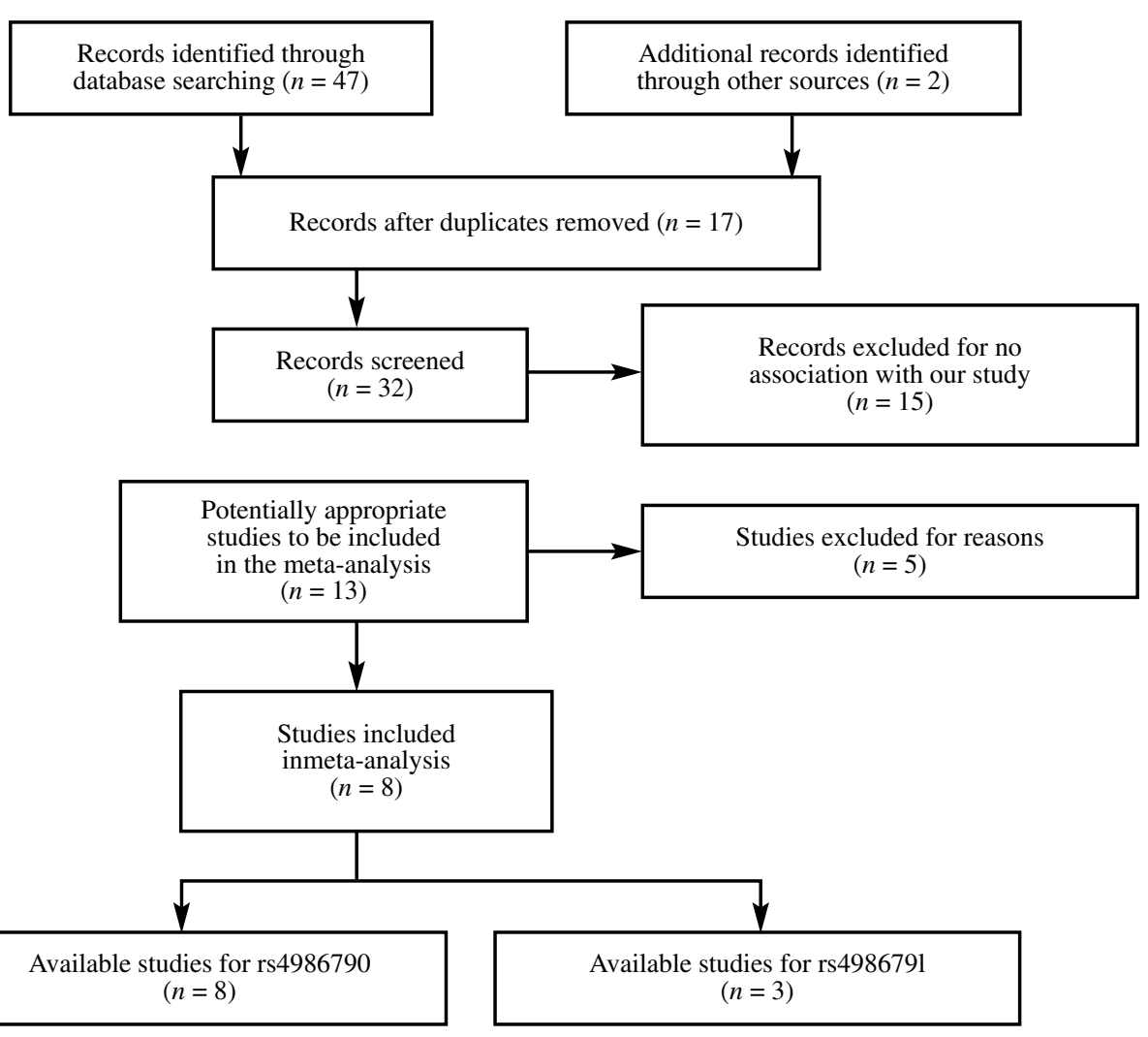

Fig. 1. Flowchart for identification of studies 


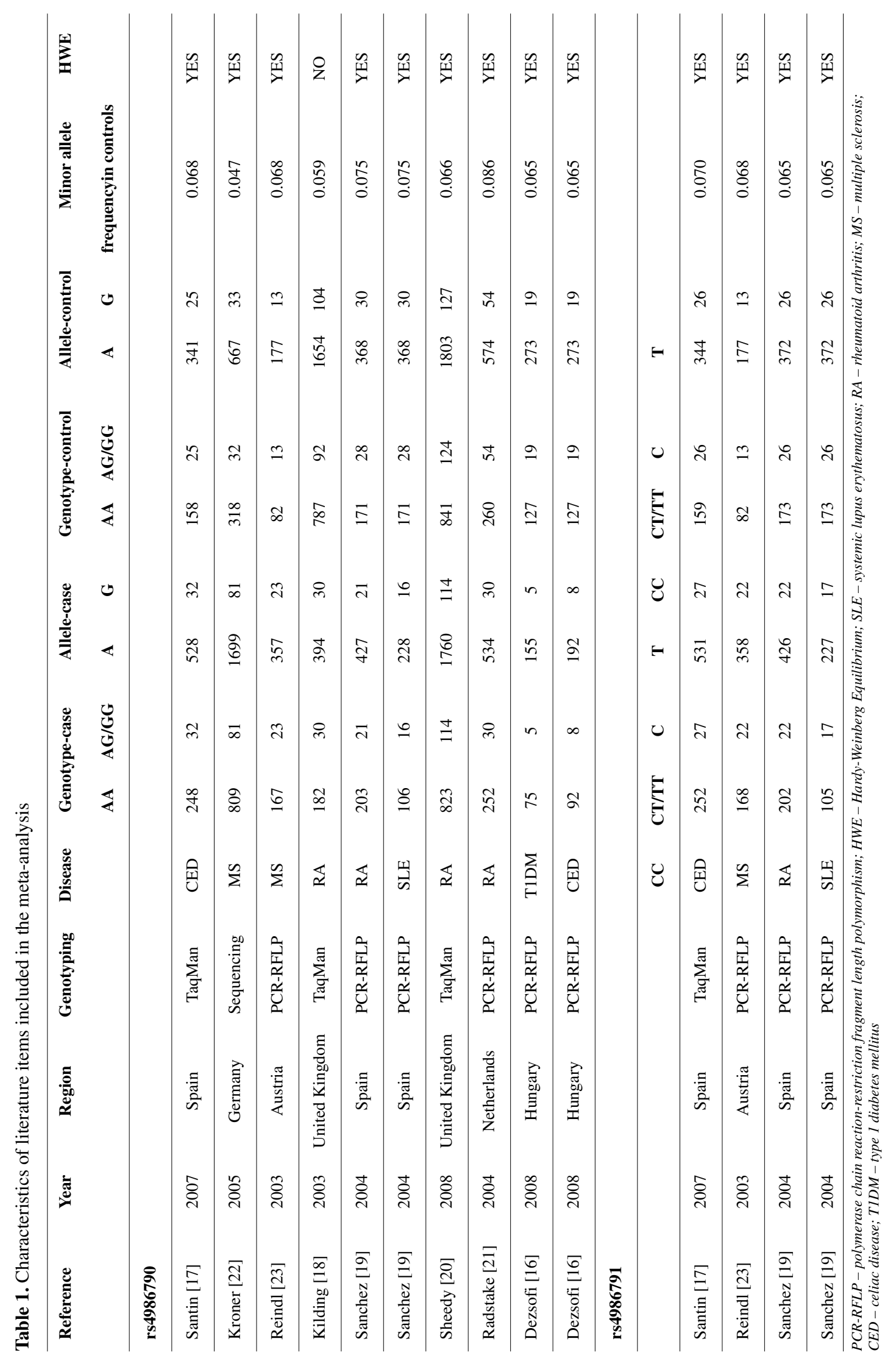


information was recorded for each study: first author, year of publication, region, number of alleles, number of genotypes, genotyping methods, disease, frequencies of minor allele in control subjects, and evidence of Hardy-Weinberg Equilibrium (HWE) in control subjects (all of the data are shown in Table 1).

\section{Statistical analysis}

The OR corresponding to the $95 \%$ confidence interval (95\% CI) was used to assess the association between TLR4 Asp299Gly and Thr399Ile polymorphisms and risk of ADs. We evaluated the risk of the minor allele on ADs compared with the major allele and then calculated the OR of minor allele carriers versus major allele homozygous using a dominant genetic model of the minor allele.

The statistical heterogeneity among studies was assessed with the Q-test and $\mathrm{I}^{2}$ statistics [24]. If there was no obvious heterogeneity, the fixed-effects model (the MantelHaenszel method) was used to estimate the summary OR [25]; otherwise, the random-effects model (the DerSimonian and Laird method) was used [26]. To explore sources of heterogeneity across studies, we did logistic meta-regression analyses. We examined the following study characteristics: publication year, region, genotyping, disease, number of alleles, number of genotypes, and minor allele frequency in controls. The HWE was assessed by Fisher's exact test (significance set at $p<0.10$ ). Publication bias was evaluated with funnel plot and Begg's rank correlation method [27]. The statistical analyses were performed by STATA 12.0 software (StataCorp., CollegeStation, TX).

\section{Results}

\section{Characteristics of studies}

Overall, eight case-control studies were available for the Asp299Gly polymorphism, including 3317 cases and 3131 controls, and three studies were available for the Thr399Ile polymorphism, including 815 cases and 479 con- trols. Study characteristics are summarized in Table 1. Three genotyping methods were used, including polymerase chain reaction-restriction fragment length polymorphism (PCR-RFLP), TaqMan probe, and direct sequencing. The diseases included type 1 diabetes, celiac disease, rheumatoid arthritis, multiple sclerosis, and systemic lupus erythematosus. The genotype distributions among the controls were consistent with HWE except the one performed by Kilding et al. [18].

\section{Quantitative synthesis}

For control subjects, G allele frequency of TLR4 Asp299Gly polymorphism was ranging from 0.047 to 0.086, T allele frequency of TLR4 Thr399Ile polymorphism was ranging from 0.068 to 0.070 . The evaluations of the association of TLR4 Asp299Gly polymorphism and TLR4 Thr399Ile polymorphism with ADs risk are shown in Table 2, Fig. 2 and Fig. 3, respectively. The TLR4 Asp299Gly and TLR4 Thr399Ile polymorphisms were not associated significantly with a risk of ADs (O Asp299Gly: $\mathrm{R}=0.86,95 \% \mathrm{CI}: 0.74-1.00$ for $\mathrm{G}$ vs. $\mathrm{A}$ and $\mathrm{OR}=0.87$, 95\% CI: $0.74-1.01$ for AG/GG vs. AA, respectively; Thr399Ile: $\mathrm{OR}=0.77,95 \% \mathrm{CI}: 0.57-1.05$ for T vs. $\mathrm{C}$ and $\mathrm{OR}=0.79,95 \% \mathrm{CI}: 0.58-1.09$ for TT/CT vs. CC, respectively). Furthermore, stratified analyses failed to find the TLR4 Asp299Gly polymorphism significantly associated with CED, RA, and MS (as shown in Fig. 2).

\section{Evaluation of heterogeneity}

There was no obvious heterogeneity among studies in overall comparisons $\left(P_{\text {heterogeneity }}=0.372, I^{2}=7.6 \%\right.$ in allele comparison for the TLR4 Asp299Gly polymorphism, $P_{\text {heterogeneity }}=0.224, I^{2}=23.8 \%$ in dominant genetic model comparison for the TLR4 Asp299Gly polymorphism, $P_{\text {heterogeneity }}=0.785, I^{2}=0 \%$ in allele comparison for the TLR4 Thr399Ile polymorphism, and $P_{\text {heterogeneity }}=0.716$, $I^{2}=0 \%$ in dominant genetic model comparison for the TLR4 Thr399Ile polymorphism, respectively).

Table 2. Associations between polymorphisms in TLR4 and multiple autoimmune diseases risk

\begin{tabular}{|c|c|c|c|c|c|c|}
\hline & \multirow[t]{2}{*}{$\mathrm{Na}^{\mathrm{a}}$} & \multirow[t]{2}{*}{ Case/control } & \multicolumn{2}{|c|}{ Allele comparison } & \multirow{2}{*}{$\begin{array}{c}\text { Dominant } \\
\text { OR }(95 \% \mathrm{CI})\end{array}$} & \multirow{2}{*}{$\frac{\text { Genetic model comparison }}{P^{\mathrm{b}}}$} \\
\hline & & & OR $(95 \% \mathrm{CI})$ & $P^{\mathbf{b}}$ & & \\
\hline \multicolumn{7}{|l|}{ rs4986790 } \\
\hline Total & 10 & $3317 / 3131$ & $0.86(0.74-1.00)$ & 0.372 & $0.87(0.74-1.01)$ & 0.224 \\
\hline Celiac disease & 2 & $380 / 329$ & $0.75(0.48-1.18)$ & 0.529 & $0.73(0.46-1.17)$ & 0.520 \\
\hline Multiple sclerosis & 2 & $1080 / 445$ & $0.96(0.67-1.37)$ & 0.774 & $0.96(0.66-1.39)$ & 0.753 \\
\hline Rheumatoid arthritis & 4 & $1655 / 2357$ & $0.88(0.73-1.06)$ & 0.071 & $0.89(0.73-1.08)$ & 0.032 \\
\hline \multicolumn{7}{|l|}{ rs4986791 } \\
\hline Total & 4 & $815 / 678$ & $0.77(0.57-1.05)$ & 0.785 & $0.79(0.58-1.09)$ & 0.716 \\
\hline
\end{tabular}




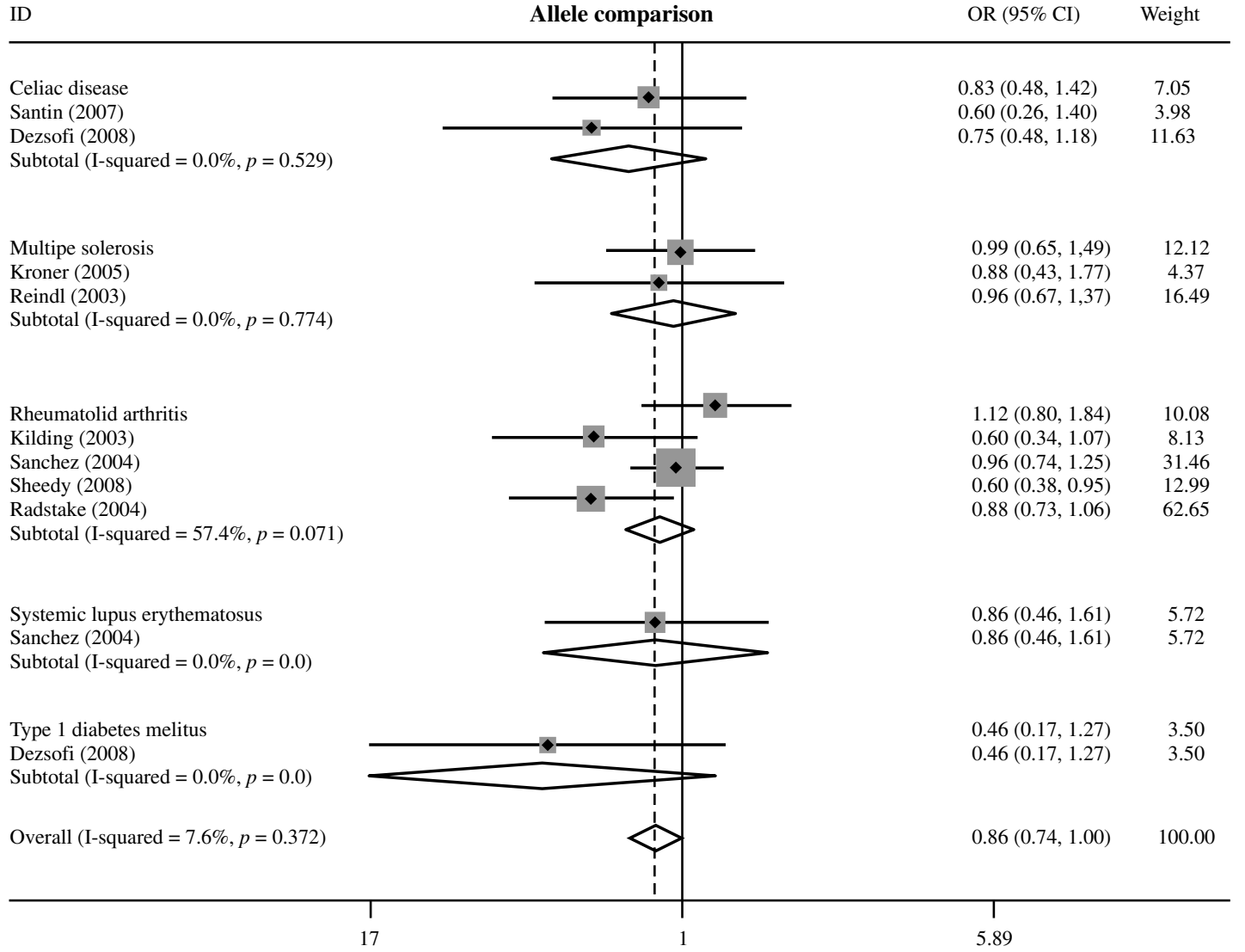

Dominant genetic model comparison

Celiac disease

Santin (2007)

Dezsofi (2008)

Subtotal (I-squared $=0.0 \%, p=0.520$ )

Multipe solerosis
Kroner $(2005)$
Reindl $(2003)$
Subtotal (I-squared $=0.0 \%, p=0.753$ )

Rheumatolid arthritis

Kilding (2003)

Sanchez (2004)

Sheedy (2008)

Radstake (2004)

Subtotal (I-squared $=65.9 \%, p=0.032$ )

Systemic lupus erythematosus

Sanchez (2004)

Subtotal (I-squared $=0.0 \%, p=0.0$ )

Type 1 diabetes melitus

Dezsofi (2008)

Subtotal (I-squared $=0.0 \%, p=0.0$ )

Overall (I-squared $=23.8 \%, p=0.224)$

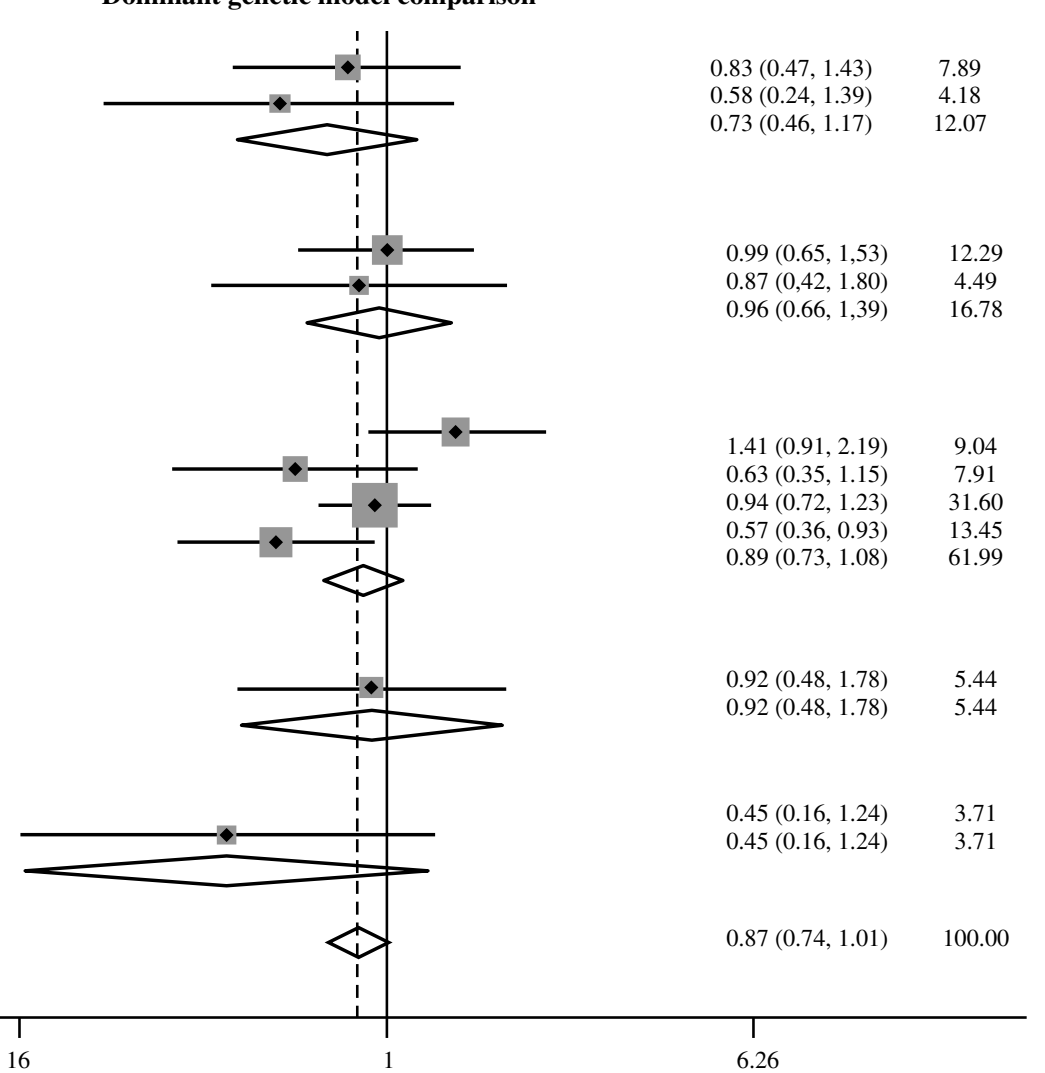

Fig. 2. Forest plot of ADs associated with distribution of TLR4 Asp299Gly polymorphism 


\begin{tabular}{ll|lll} 
ID & \multicolumn{2}{c}{ OR (95\% CI) } & Weight \\
\hline Santin (2007) & & & \\
\\
Reindl (2003)
\end{tabular}

Dominant genetic model comparison

\begin{tabular}{ll|lll}
\hline Santin (2007) & & $0.66(0.37,1.16)$ & 33.07 \\
Reindl (2003) & & $0.83(0.40,1.72)$ & 17.94 \\
Sanchez (2004) & & & $0.72(0.40,1.32)$ & 29.07 \\
\hline
\end{tabular}

Fig. 3. Forest plot of ADs associated with distribution of TLR4 Thr399Ile polymorphism
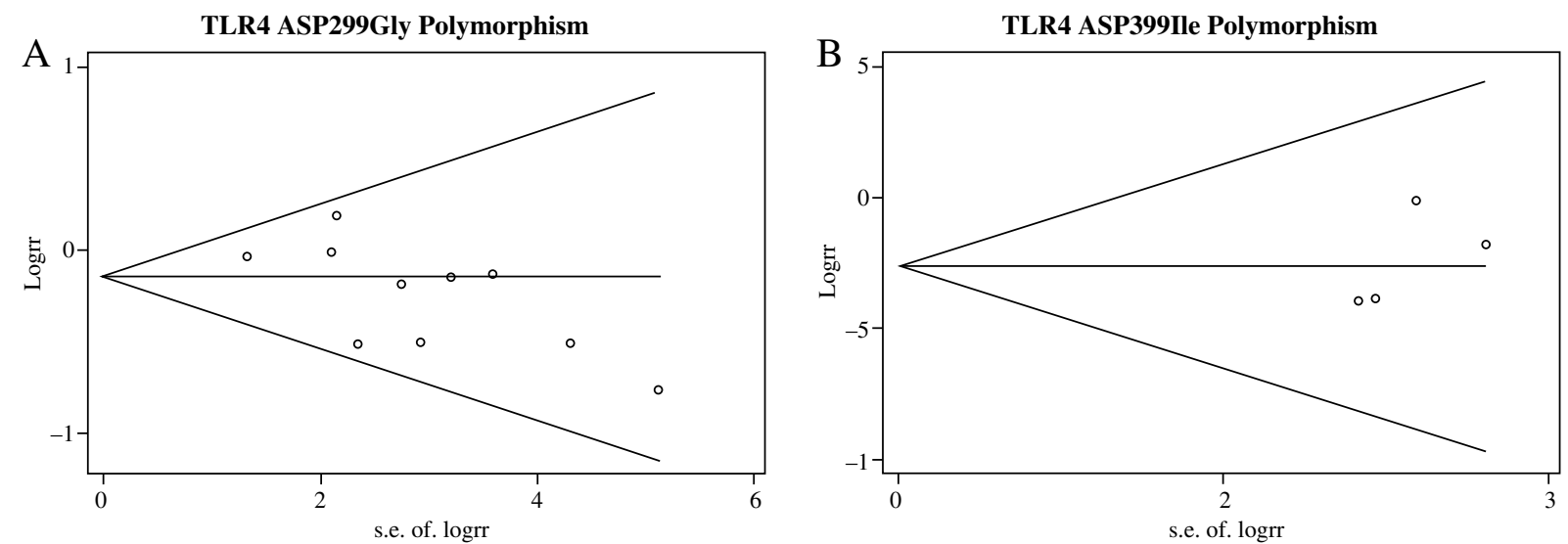

Fig. 4. Begg's funnel plot for publication bias test. Each point represents a separate study for the indicated association $\mathrm{SE}$ - standardized effect

\section{Sensitivity analysis}

The influence of a single study on the overall meta-analysis estimate was investigated by omitting one study at a time, and the omission of any study made no significant difference, indicating that our results were statistically reliable.

\section{Publication bias}

The Begg's test was performed to evaluate the publication bias of selected literature items. Figure 4 displays a funnel plot that examined both the polymorphisms and overall ADs risk included in the meta-analysis. No evidence 
of publication bias in our study was observed $(P=0.210$ for the TLR4 Asp299Gly polymorphism and $P=0.308$ for the TLR4 Thr399Ile polymorphism).

\section{Discussion}

Previous meta-analysis indicated that TLR4 polymorphisms appeared to be correlated with Crohn's disease, ulcerative colitis [8], vasculitis [9] and cancer [10], but not with sepsis [11], rheumatoid arthritis, ankylosing spondylitis [12-14], and atherosclerosis [15]. In the present study, we performed a systematic review of the association between TLR4 Asp299Gly and Thr399Ile polymorphisms and the risk of ADs. We searched PubMed, Embase, CNKI databases for all articles on the association between TLR4 polymorphisms and ADs, including type 1 diabetes, celiac disease, rheumatoid arthritis, multiple sclerosis, Grave's disease, Wegener's granulomatosis, psoriasis, primary sicca syndrome, and systemic lupus erythematosus. Finally, eight case-control studies were available for the Asp299Gly polymorphism, including 3317 cases and 3131 controls, and three studies were available for the Thr399Ile polymorphism, including 815 cases and 479 controls. Among the eight case-control studies available for the Asp299Gly polymorphism, one study was concerned with T1DM [16], two were concerned with CED [16, 17], four were concerned with RA [18-21], two were concerned with MS [22, 23], and one was concerned with SLE [19]. Our results showed that The TLR4 Asp299Gly and TLR4 Thr399Ile polymorphisms were not associated significantly with a risk of ADs both in allele comparison and in dominant genetic model comparison. Furthermore, stratified analyses failed to find the TLR4 Asp299Gly polymorphism significantly associated with CED, RA, and MS.

The TLR4 is known to activate the NF- $\kappa \mathrm{B}$ and subsequent gene expression such as cytokines and adhesion molecules [28-32]. Through the recognition of pathogens or their products, TLR4 can induce the production of proinflammatory cytokines that can contribute to the perpetuation of the inflammatory response. It is accepted that activation of the innate immune system is an important feature in the pathogenesis of Ads [33-35]. These two selected non-synonymous SNPs are located in the coding sequence, affect TLR-4 extracellular domain. Individuals possessing a co-segregating polymorphism in TLR-4 (Asp299Gly and Thr399Ile) are hyporesponsive to LPS and are more susceptible to Gram-negative bacterial infections [2, 3].

Previous studies found these two selected polymorphisms in Mexico [36] and India [37, 38]. In Asian populations, the prevalence of $r s 498690$ and $r s 4986791$ is very low. Several studies have demonstrated the absence of rs498690 and rs4986791 in the Chinese population [4-6] and in the Korean population [7]. We researched the PubMed, Embase, CNKI (China National Knowledge Infra- structure) databases for all articles on the association between TLR4 Asp299Gly and Thr399Ile polymorphisms and ADs risk, the results showed that all available articles are related to Caucasians.

Among all the available articles, one epidemiological study found that the TLR4 Asp299Gly polymorphism was associated with a decreased RA risk [21], but others failed to find the same result. Our study with accumulated data from different studies suggested that TLR4 Asp299Gly and Thr399Ile polymorphisms may not be associated with an ADs risk. Since only 8 case-control studies were available for this analysis until recently, further studies using large numbers of participants should be conducted to validate the association.

Our study evaluated the heterogeneity; there was no obvious heterogeneity among studies in overall comparisons. The influence of a single study on the overall metaanalysis estimate was investigated by omitting one study at a time, and the omission of any study made no significant difference, indicating that our results were statistically reliable. The Begg's test denied the publication bias in our study. No evidence of publication bias in our study was observed ( $P=0.210$ for the TLR4 Asp299Gly polymorphism and $P=0.308$ for the TLR4 Thr399Ile polymorphism).

The data included in the present meta-analysis have some limitations: (1) all the enrolled studies only included the association of selected polymorphisms with ADs, further studies estimating the effect of gene-gene and geneenvironment interactions may eventually provide a better, comprehensive understanding; (2) due to the low frequency of the minor allele, it is difficult for analyses by using any more genetic models.

In conclusion, this meta-analysis suggested that TLR4 Asp299Gly and TLR4 Thr399Ile polymorphisms were not involved in the development of ADs. However, welldesigned studies with a larger sample size should be conducted to confirm this result. Moreover, further studies estimating the effect of gene-gene and gene-environment interactions may eventually provide a better, comprehensive understanding.

\section{The authors declare no conflict of interests.}

\section{References}

1. Toubi E, Shoenfeld Y (2004): Toll-like receptors and their role in the development of autoimmune diseases. Autoimmunity 37: 183-188.

2. Arbour NC, Lorenz E, Schutte BC, et al. (2000): TLR4 mutations are associated with endotoxin hyporesponsiveness in humans. Nat Genet 25: 187-191.

3. Mockenhaupt FP, Cramer JP, Hamann L, et al. (2006): Tolllike receptor (TLR) polymorphisms in African children: common TLR-4 variants predispose to severe malaria. J Commun Dis 38: 230-245. 
4. Cheng PL, Eng HL, Chou MH, et al. (2007): Genetic polymorphisms of viral infection-associated Toll-like receptors in Chinese population. Transl Res 150: 311-318.

5. Chen LS, Guo QS, Xia B, et al. (2006): Polymorphism of CD14 gene promoter but not Toll-like receptor 4 is associated with colorectal cancer in Chinese patients. Chin J Dig 26: 735 738.

6. Jiang Y, Min XY, Gao JS, et al. (2007): The association between Toll-like receptor 4 gene Asp299Gly polymorphism and ulcer ative colitis and colorectal adenocarcinoma. J Changsha Medical College 12: 13-17.

7. Kim EJ, Chung WC, Lee KM, et al. (2012): Association between toll-like receptors/CD14 gene polymorphisms and inflammatory bowel disease in Korean population. J Korean Med Sci 27: 72-77.

8. Shen X, Shi R, Zhang H, et al. (2010): The Toll-like receptor 4 D299G and T399I polymorphisms are associated with Crohn's disease and ulcerative colitis: a meta-analysis. Digestion 81: 69-77.

9. Song GG, Choi SJ, Ji JD, Lee YH (2013): Toll-like receptor polymorphisms and vasculitis susceptibility: meta-analysis and systematic review. Mol Biol Rep 40: 1315-1323.

10. Zhang K, Zhou B, Wang Y, et al. (2013): The TLR4 gene polymorphisms and susceptibility to cancer: A systematic review and meta-analysis. Eur J Cancer 49: 946-954.

11. Zhu L, Li X, Miao C (2012): Lack of association between TLR4 Asp299Gly and Thr399Ile polymorphisms and sepsis susceptibility: a meta-analysis. Gene 501: 213-218.

12. Xu WD, Liu SS, Pan HF, Ye DQ (2012): Lack of association of TLR4 polymorphisms with susceptibility to rheumatoid arthritis and ankylosing spondylitis: a meta-analysis. Joint Bone Spine 79: 566-569.

13. Xu WD, Liu SS, Pan HF, Ye DQ (2012): Lack of association of TLR4 polymorphisms with susceptibility to rheumatoid arthritis and ankylosing spondylitis: a meta-analysis. Joint Bone Spine 79: 566-569.

14. Lee YH, Bae SC, Song GG (2013): Meta-analysis demonstrates association between TLR polymorphisms and rheumatoid arthritis. Genet Mol Res 12: 328-334.

15. Zhang K, Zhang L, Zhou B, et al. (2012): Lack of association between TLR4 Asp299Gly polymorphism and atherosclerosis: evidence from meta-analysis. Thromb Res 130: e203-208.

16. Dezsofi A, Szebeni B, Hermann CS, et al. (2008): Frequencies of genetic polymorphisms of TLR4 and CD14 and of HLADQ genotypes in children with celiac disease, type 1 diabetes mellitus, or both. J Pediatr Gastroenterol Nutr 47: 283-287.

17. Santin I, Castellanos-Rubio A, Hualde I, et al. (2007): Tolllike receptor 4 (TLR4) gene polymorphisms in celiac disease. Tissue Antigens 70: 495-498.

18. Kilding R, Akil M, Till S, et al. (2003): A biologically important single nucleotide polymorphism within the toll-like receptor-4 gene is not associated with rheumatoid arthritis. Clin Exp Rheumatol 21: 340-342.

19. Sánchez E, Orozco G, López-Nevot MA, et al. (2004): Polymorphisms of toll-like receptor 2 and 4 genes in rheumatoid arthritis and systemic lupus erythematosus. Tissue Antigens 63: 54-57.

20. Sheedy FJ, Marinou I, O’Neill LA, Wilson AG (2008): The Mal/TIRAP S180L and TLR4 G299D polymorphisms are not associated with susceptibility to, or severity of, rheumatoid arthritis. Ann Rheum Dis 67: 1328-1331.

21. Radstake TR, Franke B, Hanssen S, et al. (2004): The Toll-like receptor 4 Asp299Gly functional variant is associated with decreased rheumatoid arthritis disease susceptibility but does not influence disease severity and/or outcome. Arthritis Rheum 50: 999-1001.

22. Kroner A, Vogel F, Kolb-Mäurer A, et al. (2005): Impact of the Asp299Gly polymorphism in the toll-like receptor 4 (TLR-4) gene on disease course of multiple sclerosis. J Neuroimmunol 165: 161-165.

23. Reindl M, Lutterotti A, Ingram J, et al. (2003): Mutations in the gene for toll-like receptor 4 and multiple sclerosis. Tissue Antigens 61: 85-88.

24. Higgins JP, Thompson SG (2002): Quantifying heterogeneity in a meta-analysis. Stat Med 21: 1539-1558.

25. Mantel N, Haenszel W (1959): Statistical aspects of the analysis of data from retrospective studies of disease. J Natl Cancer Inst 22: 719-748.

26. DerSimonian R, Laird N (1986): Meta-analysis in clinical trials. Control Clin Trials 7: 177-188.

27. Begg CB, Mazumdar M (1994): Operating characteristics of a rank correlation test for publication bias. Biometrics 50: 10881101.

28. Urcelay E, Blanco-Kelly F, de Las Heras V, et al. (2007): TLR4 haplotypes in multiple sclerosis: a case-control study in the Spanish population. J Neuroimmunol 192: 215-218.

29. Chansrichavala P, Chantharaksri U, Sritara P, Chaiyaroj SC (2009): Atorvastatin attenuates TLR4-mediated NF-kappaB activation in a MyD88-dependent pathway. Asian Pac J Allergy Immunol 27: 49-57.

30. Ma CX, Yin WN, Cai BW, et al. (2009): WITHDRAWN: Activation of TLR4/NF-kappaB signaling pathway in early brain injury after subarachnoid hemorrhage. Neurol Res.

31. Marr N, Turvey SE (2012): Role of human TLR4 in respiratory syncytial virus-induced NF-kappaB activation, viral entry and replication. Innate Immun 18: 856-865.

32. Oleś D., Szczepankiewicz A (2012): Role of Toll-like receptors in the development of allergic inflammation in asthma. Postep Derm Alergol 29: 275-278.

33. Klinman D (2003): Does activation of the innate immune system contribute to the development of rheumatoid arthritis? Arthritis Rheum 48: 590-593.

34. Compston A, Coles A (2002): Multiple sclerosis. Lancet 359: 1221-1231.

35. Wen L, Peng J, Li Z, Wong FS (2004): The effect of innate immunity on autoimmune diabetes and the expression of Tolllike receptors on pancreatic islets. J Immunol 172: 3173-3180.

36. Garza-Gonzalez E, Bosques-Padilla FJ, Mendoza-Ibarra SI, et al. (2007): Assessment of the toll-like receptor 4 Asp299Gly, Thr399Ile and interleukin-8 -251 polymorphisms in the risk for the development of distal gastric cancer. BMC Cancer 7: 70.

37. Pandey S, Mittal RD, Srivastava M (2009): Impact of Toll-like receptors [TLR] 2 (-196 to $-174 \mathrm{del}$ ) and TLR 4 (Asp299Gly, Thr399Ile) in cervical cancer susceptibility in North Indian women. Gynecol Oncol 114: 501-505.

38. Srivastava K, Srivastava A, Kumar A, Mittal B (2010): Significant association between toll-like receptor gene polymorphisms and gallbladder cancer. Liver Int 30: 1067-1072. 